\title{
Malignant-looking thyroid nodules with size reduction: core needle biopsy results
}

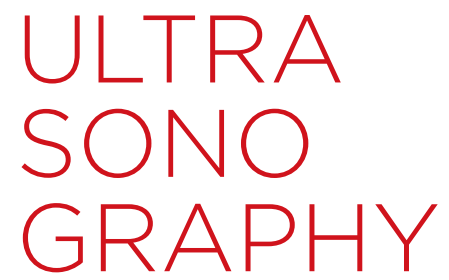

\author{
Ha Young Lee ${ }^{1,2}$, Jung Hwan Baek', Eun Ju Ha ${ }^{1,3}$, Jee Won Park ${ }^{1,4}$, Jeong Hyun Lee', \\ Dong Eun Song ${ }^{5}$, Young Kee Shong ${ }^{6}$ \\ 'Department of Radiology and the Research Institute of Radiology, Asan Medical Center, \\ University of Ulsan College of Medicine, Seoul; ${ }^{2}$ Department of Radiology, Inha University \\ School of Medicine, Incheon; ${ }^{3}$ Department of Radiology, Ajou University School of Medicine, \\ Suwon; Departments of ${ }^{4}$ Health Medicine, ${ }^{5}$ Pathology, and ${ }^{6}$ Endocrinology and Metabolism, \\ Asan Medical Center, University of Ulsan College of Medicine, Seoul, Korea
}

Purpose: The aim of this study was to evaluate whether malignant-looking thyroid nodules with size reduction were malignant or not.

Methods: From November 2010 to July 2011, we retrospectively enrolled 16 patients with 16 nodules (11 females and five males; mean age, 55 years) who underwent core needle biopsy (CNB), and whose thyroid nodules had malignant ultrasonographic (US) features, although they showed size reduction ( $>20 \%$ decrease in maximum diameter) during the follow-up period (mean, $37 \pm 27$ months). The histologic findings of the CNB specimen were reviewed and correlated with the US findings. US studies were analyzed for their internal content, shape, margin, echogenicity, the presence of microcalcification and macrocalcification, inner isoechoic rim, and low-echoic halo.

Results: All nodules were confirmed as benign by CNB. Pathologic analysis was available for 12 CNB specimens. US imaging showed central hypoechogenicity or marked hypoechogenicity in all cases and a peripheral isoechoic rim in 15 nodules. US-pathologic correlation showed that the central hypoechoic area was primarily composed of fibrosis (12/12) and hemorrhage (8/12) and that the isoechoic rim was composed of follicular cells.

Conclusion: In our study, the CNB results of all of the malignant-looking thyroid nodules with size reduction were benign and were primarily composed of internal fibrosis and hemorrhage. Understanding these US and pathologic features could prevent repeated fine-needle aspiration or unnecessary diagnostic surgery.

Keywords: Thyroid nodule; Biopsy, fine-needle; Biopsy, large-core needle; Ultrasonography

\section{Introduction}

The criteria for differentiating benign from malignant nodules in ultrasonographic (US) imaging are well-established, and the major guidelines recommend fine-needle aspiration (FNA) under US guidance for nodules with malignant US features [1-3]. Several studies have reported that initially

\section{ORIGINAL ARTICLE}

http://dx.doi.org/10.14366/usg. 15082 pISSN: 2288-5919 - elSSN: 2288-5943

Ultrasonography 2016:35:327-334

Received: December 23, 2015

Revised: March 30, 2016

Accepted: March 31, 2016

Correspondence to:

Jung Hwan Baek, MD, Department of Radiology and Research Institute of Radiology, Asan Medical Center, University of Ulsan College of Medicine, 88 Olympic-ro 43-gil, Songpa-gu, Seoul 05505, Korea

Tel. +82-2-3010-4348

Fax. +82-2-476-0090

E-mail: radbaek@naver.com

\begin{abstract}
This is an Open Access article distributed under the terms of the Creative Commons Attribution NonCommercial License (http://creativecommons.org/ licenses/by-nc/3.0/) which permits unrestricted noncommercial use, distribution, and reproduction in any medium, provided the original work is properly cited.
\end{abstract}

Copyright (C) 2016 Korean Society of Ultrasound in Medicine (KSUM)

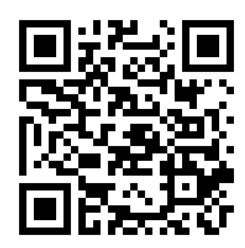

How to cite this article:

Lee HY, Baek JH, Ha EJ, Park JW, Lee JH, Song $\mathrm{DE}$, et al. Malignant-looking thyroid nodules with size reduction: core needle biopsy results. Ultrasonography. 2016 0ct;35(4):327-334. 
benign thyroid nodules undergo size reduction and show malignant features on follow-up US [4-6]. This unusual feature can also be seen in thyroid nodules following their treatment using ethanol or radiofrequency ablation [7]. Therefore, the correct diagnosis of these nodules depends on the history of the patient's minimally invasive treatment or on previously obtained sonograms.

Regarding the management of these nodules, if investigators encounter thyroid nodules with malignant US features but without definite, previous information, that is, known history of ethanol or radiofrequency ablation and/or previous sonograms, they should biopsy the nodules. Even if the biopsy results are benign, repeat FNA or diagnostic surgery will still be necessary due to their malignant US features [8].

Therefore, our study was performed to test the hypothesis that thyroid nodules with size reduction, although with malignant US features, are benign, degenerating nodules rather than malignancies. To test this hypothesis, we evaluated the follow-up results regarding these nodules as well as the histological analysis of their core needle biopsy (CNB) specimens.

\section{Materials and Methods}

\section{Patient Population}

This retrospective study was approved by our Institutional Review Board, and informed consent was waived for use of the data in the research study; however, informed consent for all procedures had already been obtained from each patient before procedures were performed.

Computerized medical records and sonograms of 3,114 patients who had undergone US-guided FNA for thyroid nodules at our institution between November 2010 and July 2011 were reviewed. Among these patients, those with thyroid nodules showing all of the following criteria were enrolled: (1) thyroid nodules showing malignant US features, (2) size reduction seen on follow-up US (size reduction was defined as $>20 \%$ decrease in the longest diameter), (3) follow-up of more than 1 year, and (4) undergoing CNB. The final diagnosis was based on the results of CNB and surgical pathologic examination.

The criteria for classifying a case as having malignant features on US imaging included at least one of the following: (1) marked hypoechogenicity, (2) the presence of microcalcification or macrocalcification, (3) taller-than-wide shape, and (4) a spiculated margin $[3,9,10]$. Ultimately, 16 nodules from 16 patients (11 females and five males; mean age, 55 years; range, 33 to 63 years) were included in our study.

\section{US and US-Guided FNA or CNB}

US was performed using one of two US systems, an iU22 unit (Philips Healthcare, Bothell, WA, USA) or an EUB-7500 unit (Hitachi Medical Systems, Tokyo, Japan) equipped with a linear high-frequency probe (5-14 MHz). All US and US-guided procedures were performed by clinically experienced radiologists with 7-17 years of clinical experience performing and evaluating thyroid sonograms.

US-guided FNA was performed using a 23-gauge needle attached to a $10-\mathrm{mL}$, disposable, plastic syringe. US-guided CNBs were performed using a disposable, 18-gauge, double-action, springactivated needle (1.1- or 1.6-cm excursion, TSK Ace-cut, Create Medic, Yokohama, Japan). After local anesthesia with $1 \%$ lidocaine, the end of the biopsy needle was advanced into the edge of or within the nodule using a free-hand technique, and after which the stylet and cutting cannula of the needle were fired sequentially. After FNA or CNB, each patient was observed, and a firm, local compression of the biopsy site was applied for 10-20 minutes $[8,11]$.

\section{Analysis of the US Findings and Histopathologic Results}

Sonograms were retrospectively reviewed independently by two clinically experienced radiologists (H.Y.L. and J.H.B., with 8 and 17 years, respectively, of clinical experience performing and evaluating thyroid US). Any diagnostic discrepancies between the two reviewers were resolved by consensus. Individual sonograms were analyzed for the internal content (solid, predominantly solid, predominantly cystic, or cystic), shape (oval-to-round, irregular, or taller-than-wide), margin (smooth, ill-defined, or spiculated), echogenicity (markedly hypoechoic, hypoechoic, isoechoic, or hyperechoic), the presence of microcalcification and macrocalcification, an inner isoechoic rim, and a low-echoic halo $[4,8]$. An inner isoechoic rim was defined as a thin, continuous, isoechoic rim that lines the perimeter of a nodule, and which was presumed to have a histologic correspondence to an intact solid component at the periphery of a pre-existing cystic nodule (Figs. 1, 2) [4]. A low-echoic halo was defined as a hypoechoic rim surrounding the outer margin of a nodule (Figs. 1, 2) [4]. All of the other US features were based on previously published criteria $[3,4]$.

Histopathologic analysis of the CNB and the surgical specimens was available in 12 and two patients, respectively, and which were retrospectively reviewed by one clinically experienced cytopathologist (D.E.S., with 9 years of clinical experience in thyroid cytopathology). As the diagnostic criteria of CNB have not been standardized for thyroid nodules, diagnoses based on CNB histology were categorized into the six categories of the Bethesda System as follows $[8,12,13]$. A non-diagnostic CNB reading included the absence of any identifiable follicular thyroid tissue, the presence of only a normal thyroid gland, and tissue containing only a few 
follicular cells that were insufficient for reaching a diagnosis. The benign CNB reading included colloid nodules, nodular hyperplasia, lymphocytic thyroiditis, Graves' disease, and postpartum thyroiditis. The atypia with undetermined significance reading for CNB included nodules in which some atypical cells were present but which were not sufficient for a diagnosis of suspicious malignancy or malignancy.
Nodules with histologic features favoring follicular neoplasm were categorized as "suspicious for follicular neoplasm" or "follicular neoplasm." The "suspicious for malignancy" or "malignancy" CNB readings were designated when the specimen exhibited atypical features that were insufficient for a definite diagnosis of malignancy or had unequivocal features of cancer, respectively

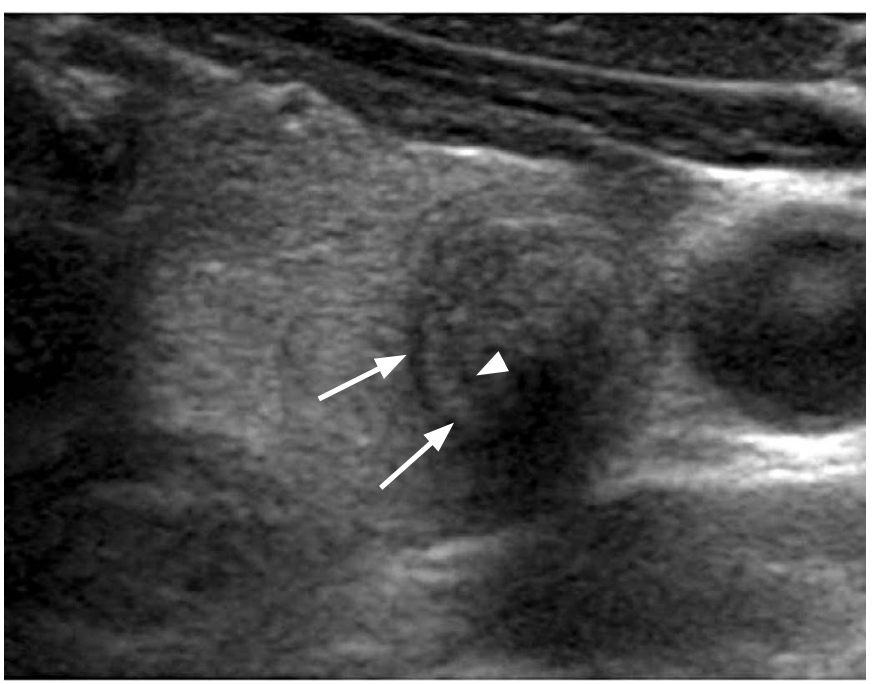

A

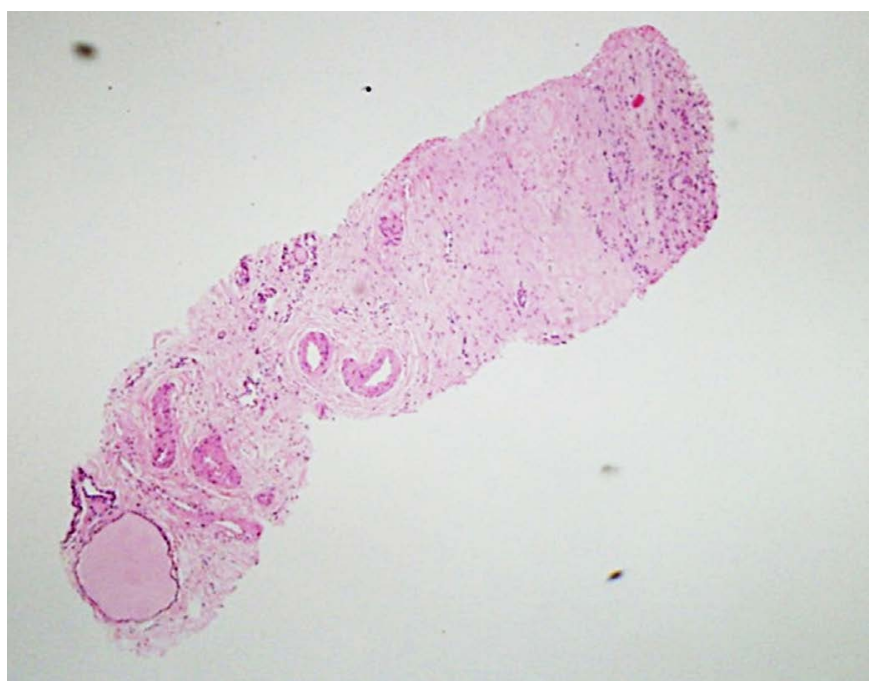

B

Fig. 1. A 61-year-old man with a degenerating benign nodule.

A. Transverse sonogram shows a 1.2-cm, hypoechoic solid nodule with an inner isoechoic rim (arrowhead) and a peripheral, low-echoic halo (arrows) in the left thyroid lobe. Subsequent core needle biopsy (CNB) confirmed it as degenerating nodular hyperplasia. B. A CNB specimen shows tissue consisting of a central portion of severe fibrosis and a periphery of a few follicular cells at the corresponding areas seen on sonogram $(H \& E, \times 40)$.

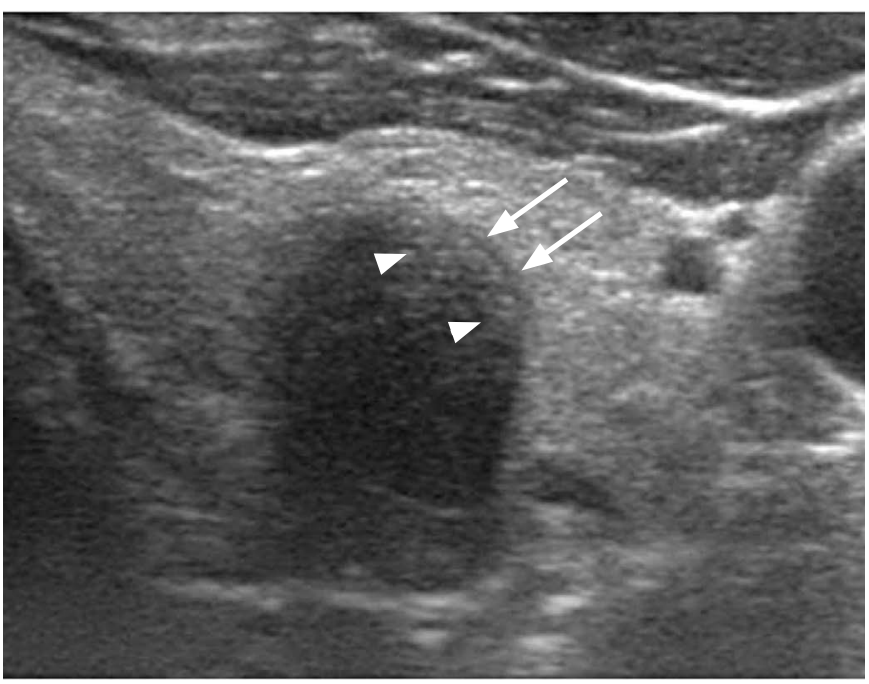

A

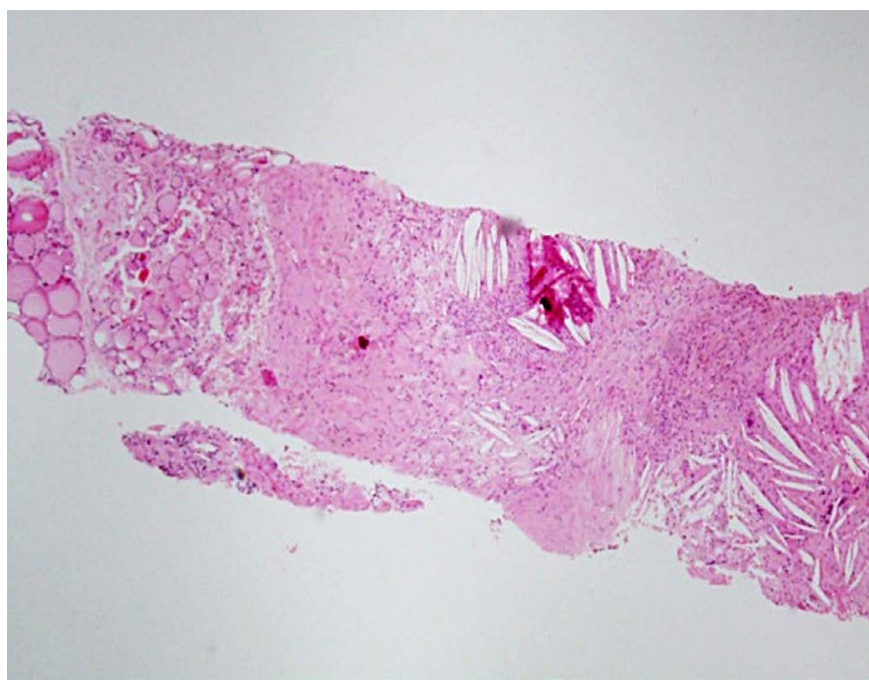

B

Fig. 2. A 63-year-old man with a degenerating benign nodule.

A. Transverse sonogram shows a 0.8-cm, markedly hypoechoic, solid nodule with an inner isoechoic rim (arrowheads) and a low-echoic halo (arrows) in the right thyroid lobe. B. A core needle biopsy specimen confirmed nodular hyperplasia with fresh hemorrhage and severe fibrosis $(H \& E, \times 40)$. 
$[8,13,14]$. The histological changes in response to degeneration in pre-existing nodules, such as hemorrhage, fibrosis, calcification, granulation tissue, infarction, and atypia, were reviewed $[8,15]$. The histopathologic features of a CNB specimen were correlated with the US features in each nodule.

\section{Results}

The demographic data, histologic diagnosis, and US features are presented in Tables 1 and 2. The results of initial FNA biopsy for the 16 nodules were benign in 11 patients and non-diagnostic in five. All nodules had malignant US features at the time of the CNB, although five of 16 nodules (31\%) had malignant US features seen on the initial US. The sizes of 16 nodules ranged from 11 to $65 \mathrm{~mm}$ (mean, $21.3 \mathrm{~mm}$ ) in longest diameter on the initial US, and the sizes ranged from 3 to $26 \mathrm{~mm}$ (mean, $9.8 \mathrm{~mm}$ ) on the final US. The average reduction rate of the nodules was $47.9 \% \pm 20.8 \%$, and ranging from $26.3 \%$ to $89.2 \%$. The proportions of the solid component were predominantly cystic in $25 \%$ (4/16), predominantly solid in $25 \%(4 / 16)$, and solid in 50\% (8/16) of the nodules on the initial US. An inner, isoechoic rim was present in 15 (94\%) and a low-echoic halo in 13 of the nodules (81\%). An inner isoechoic halo was present in all of the 13 nodules with low-echoic halo.

CNB specimens of 12 nodules were retrieved for histological analysis from the Department of Pathology of our institution. CNB specimens of four patients were not available to review because they were not retrievable from our pathology department. Among the 12 nodules, the central portions were mainly composed of fibrosis $(n=12,100 \%)$, hemorrhage $(n=8,67 \%)$, atypia $(n=1,8 \%)$, and relatively few follicular cells in all cases, and which corresponded to the hypo- or marked hypoechogenicity seen on US (Figs. 1, 2). The peripheral portions had a sufficient number of follicular cells for diagnosis in 11 cases (Figs. 1, 2), and which corresponded to the US feature of the inner isoechoic rim. Two patients underwent total thyroidectomy because of discordant image-pathology results. They were finally diagnosed with nodular hyperplasia and Hürthle cell adenoma, respectively. The central portion of each nodule, composed of hematoma and fibrosis with a few follicular cells, was identified from the surgical specimen in both cases. The histologic results of the 12 nodules are summarized in Table 3.

\section{Discussion}

Our study demonstrated that all 16 thyroid nodules with malignant US features and with reduction in size during the follow-up period were found to be benign rather than malignant. On histological review of the CNB specimens of 12 nodules, the nodules consisted primarily of fibrosis $(100 \%)$ and hemorrhage $(67 \%)$. In terms of the histologic features of these degenerating nodules, the malignant US features were derived from fibrosis and hemorrhage. There were relatively few follicular cells in the center of the nodules, although there was a substantial number in the periphery in $91.7 \%$ (11/12)

Table 1. Clinical data and histological diagnosis of nodules

\begin{tabular}{ccccccl}
\hline Case No. & Age $(\mathrm{yr})$ & Sex & F/U interval $(\mathrm{mo})$ & Initial diameter $(\mathrm{mm})$ & F/U diameter $(\mathrm{mm})$ & \multicolumn{1}{c}{ Histological diagnosis } \\
\hline 1 & 62 & F & 22 & 15 & 11 & Nodular hyperplasia \\
2 & 37 & F & 14 & 11 & 8 & Benign fibrotic nodule \\
3 & 63 & M & 15 & 11 & 8 & Nodular hyperplasia \\
4 & 54 & F & 16 & 19 & 14 & Nodular hyperplasia \\
5 & 54 & F & 12 & 17 & 10 & Nodular hyperplasia \\
6 & 59 & F & 34 & 17 & 11 & Nodular hyperplasia \\
7 & 62 & M & 51 & 13 & 4 & Nodular hyperplasia \\
8 & 33 & F & 12 & 16 & 3 & Organizing hematoma \\
9 & 61 & F & 99 & 65 & 7 & Nodular hyperplasia \\
10 & 61 & F & 53 & 13 & 9 & Nodular hyperplasia \\
11 & 59 & F & 67 & 16 & 12 & Nodular hyperplasia \\
12 & 61 & M & 30 & 24 & 26 & Nodular hyperplasia \\
13 & 63 & F & 77 & 41 & 13 & Nodular hyperplasia with hematoma \\
14 & 39 & M & 44 & 30 & 8 & Nodular hyperplasia \\
15 & 61 & F & 47 & 13 & 6 & Nodular hyperplasia \\
16 & 51 & M & 15 & 19 & & Hürthle cell adenoma
\end{tabular}

F/U, follow-up; F, female; M, male. 
Table 2. US features of 16 thyroid nodules with benign histology that showed a gradual size decrease on follow-up US

\begin{tabular}{|c|c|c|}
\hline US characteristic & Initial US feature & Follow-up US feature \\
\hline \multicolumn{3}{|l|}{ Internal content } \\
\hline Solid & $8(50)$ & $16(100)$ \\
\hline Predominantly solid & $4(25)$ & - \\
\hline Predominantly cystic & $4(25)$ & - \\
\hline \multicolumn{3}{|l|}{ Shape } \\
\hline Ovoid-to-round & $16(100)$ & $12(75)$ \\
\hline Irregular & - & $4(25)$ \\
\hline \multicolumn{3}{|l|}{ Margin } \\
\hline Smooth & $9(56)$ & $1(6)$ \\
\hline III-defined & $6(38)$ & $13(81)$ \\
\hline Spiculated & $1(6)$ & $2(13)$ \\
\hline \multicolumn{3}{|l|}{ Echogenicity } \\
\hline Markedly hypoechoic & $3(19)$ & $6(38)$ \\
\hline Hypoechoic & $8(50)$ & $10(62)$ \\
\hline Isoechoic & $5(31)$ & - \\
\hline \multicolumn{3}{|l|}{ Calcification } \\
\hline Microcalcification & $1(6)$ & $2(13)$ \\
\hline Macrocalcification & $2(13)$ & $3(19)$ \\
\hline Rim calcification & $1(6)$ & $1(6)$ \\
\hline Inner isoechoic rim & 0 & $15(94)$ \\
\hline Low-echoic halo & $5(31)$ & $13(87)$ \\
\hline
\end{tabular}

Values are presented as number (\%).

a) Ultrasonographic (US) features at the time of core needle biopsy. The numbers in parentheses are percentages.

Table 3. Histological results of 12 thyroid nodules found in coreneedle biopsy specimens

\begin{tabular}{lc}
\hline \multicolumn{1}{c}{ Variable } & No. (\%) \\
\hline Center & \\
Hemorrhage & $8(67)$ \\
Fibrosis & $12(100)$ \\
Calcification & $3(25)$ \\
Granulation & $2(17)$ \\
Infarction & 0 \\
Atypia & $1(8)$ \\
Periphery & \\
Adequate follicular cells & $11(92)$ \\
\hline
\end{tabular}

of the nodules. Targeting the central portion of a nodule may pose a higher risk of a non-diagnostic rate on FNA. CNB including the center and periphery of the nodules could minimize non-diagnostic results as well as provide histologic information regarding the degenerative changes.
It is well known that degeneration of cystic or partly cystic thyroid nodules shows malignant US features with reduction in the nodule size [4-6]. Sohn et al. [6] suggested that serial sonograms are helpful for diagnosing degenerating cystic thyroid nodules. In their study, all malignant-looking thyroid nodules with size reduction after FNA had a cystic component seen on the initial US. In our study, four thyroid nodules were predominantly cystic on the initial US, but others were predominantly solid $(n=4)$ or solid $(n=8)$. These results suggest that not only cystic nodules but also solid nodules can show degenerative changes. Therefore, degenerating, solid thyroid nodules should not be regarded as malignancies. Malignant nodules also have the possibility of spontaneous degeneration, although there was no malignant case in the present study. Falsepositive or disappearing papillary thyroid carcinomas on surgery infrequently occur, and reactive histological changes from needle passage were found to be one of the major causes of this unusual phenomenon $[16,17]$. The US features of those malignant nodules with degenerative changes may differ from those of benign nodules; however, the US features of these nodules were not described in the literature. In these unusual circumstances, review of sonograms prior to the FNA procedure or surgery could be the only clue to diagnosis.

Ko et al. [4] reported that $46 \%$ of collapsing cystic nodules were misclassified as malignant on US because they showed marked hypoechogenicity, microcalcification, and/or spiculated margins. They suggested more specific US findings for degenerating nodules than those obtained for papillary thyroid carcinomas, that is, an inner isoechoic rim and perinodular halo, although these findings were not correlated with histology. Our study showed similar US features. An inner isoechoic rim and low-echoic halo were also common findings in the degenerating nodules. Correlation of US and pathologic features of a CNB specimen showed comprehensive and useful information for diagnosing degenerating thyroid nodules. A hypoechoic or markedly hypoechoic central area showed fibrosis and hemorrhage. These central hypoechoic areas were seen to contain few follicular cells on histology, but the inner isoechoic rim seen on US contained abundant follicular cells. These findings suggest that central hemorrhage or infarction resulted in fibrosis showing a low echo on US and that the peripheral, inner-isoechoic rim is remaining thyroid tissue compressed by central hemorrhage (Fig. 3). Understanding of these US and pathologic features can reduce nondiagnostic FNA results by targeting the peripheral isoechoic area. In addition, CNB targeting both the central, low-echoic portion and the peripheral, isoechoic portion can provide comprehensive information for identifying degenerating thyroid nodules.

The cause of malignant US features in benign thyroid nodules is not well established. Several studies have reported that low echogenicity, one of the malignant US features, is related to 


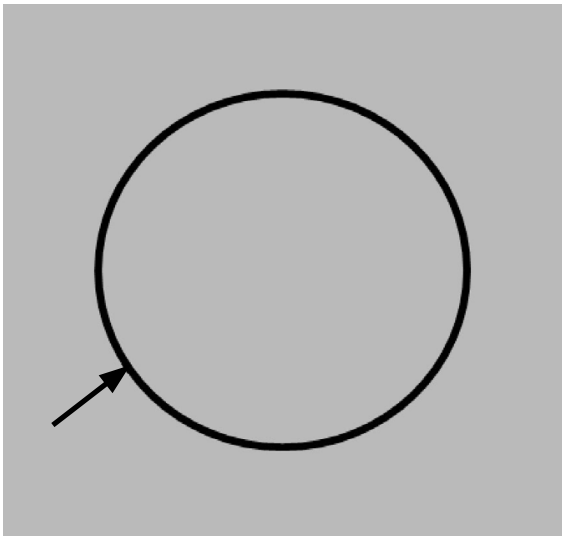

A

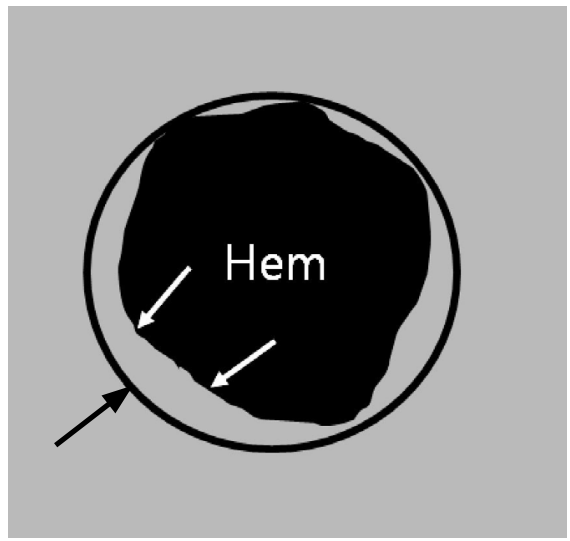

B

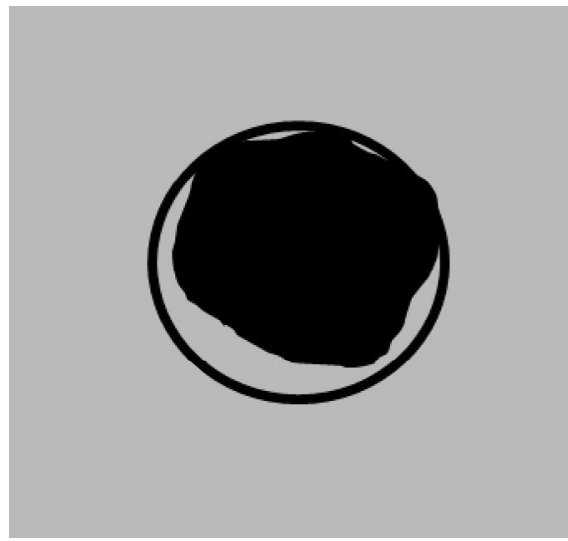

C

Fig. 3. Schematic, sequential feature of a degenerating nodule corresponding to Fig. 1.

A. An isoechoic nodule is surrounded by a hypoechoic rim (arrow) in the thyroid gland. B. Internal hemorrhage (Hem) compresses the remaining isoechoic solid portion of the nodule (arrows). C. Nodule is gradually contracted with degenerative changes such as fibrosis, infarction, and calcifications.

the fibrotic component of thyroid nodules $[18,19]$. Similarly, all degenerating nodules in our study were markedly hypoechoic or had a hypoechoic US feature and were primarily composed of fibrosis. Fibrosis in degenerating nodules has been known to be caused by hemorrhage, infarction, and degeneration $[8,20]$. Ha et al. [8] performed CNB for thyroid nodules with initially benign FNA results, but which showed malignant US features. They concluded that benign thyroid nodules could show malignant US features because of fibrosis, hemorrhage, and calcifications. These observations are similar to those of our study.

Several studies have reported the natural history of thyroid nodules [21-23]. Size reduction or nodule disappearance in $52 \%$ of untreated, benign thyroid nodules has been reported, and these changes were more frequently observed in cystic nodules [23]. Other restudies have assessed the gradual size decrease of benign cystic or partially cystic thyroid nodules which occurred spontaneously or following needle aspiration, and these nodules tended to have malignant features seen on US [4-6]. Recently, Ito et al. [24] reported a benign solid nodule with a $97 \%$ decrease in nodule volume, and which showed malignant US features during the 16 -year follow-up period. In our study, $75 \%$ of the degenerating nodules (12/16) were initially solid (50\%) and predominantly solid (25\%). Although these nodules might be concluded as to be benign due to their size reduction, confident diagnoses could not be made because the nodules were initially solid and showed malignant features on follow-up US. Moreover, degenerative changes, including severe fibrosis and hemorrhage, as observed in our study, could result in insufficient diagnostic results on followup FNA. CNB improved the diagnostic confidence for these benign nodules with suspicious US features by allowing an understanding of the histologic changes and may thus prevent repeated FNA or diagnostic surgery.

In our study, two patients underwent diagnostic surgery due to malignant US features, although the CNB results were benign. Recently, CNB has been reported to be a valuable diagnostic tool that can be used to reduce the incidence of diagnostic surgery and/or repeated FNA in patients with previously non-diagnostic $[11,25]$ or indeterminate FNA $[26,27]$ results as well as discordant US-pathology results [8]. Yeon et al. [11] reported that diagnostic surgery was prevented by CNB in $96 \%$ of their patients with two sets of non-diagnostic FNA results. CNB would prevent further diagnostic surgery or repeated FNA in these malignancy-mimicking degenerating nodules by providing an understanding of the histologic changes of degeneration. Our study results could, thus, reduce unnecessary diagnostic surgery for thyroid nodules with malignant US features but with reduction in size.

Our study has some limitations, including its retrospective study design and small number of patients, which may have caused a selection bias. However, our study has a definite clinical impact when considering that the incidence of solid or predominantly solid nodules showing gradual size reduction is relatively rare, and the number of cases with histologic confirmation using CNB or surgical excision is limited. Nevertheless, our results require additional, prospective studies with larger patient populations. Specific statistical analysis was not performed because the purpose of our study was to identify the benignancy of degenerating nodules according to the pathology correlation.

To conclude, we found that all of the 16 nodules with malignant 
US features that showed gradual size reduction on follow-up were confirmed to be benign. Our study results could help CNB prevent further diagnostic surgery or repeated FNA for thyroid nodules with malignant US features but with reduction in size, by providing an understanding of the histologic changes of degeneration.

ORCID: Ha Young Lee: http://orcid.org/0000-0003-2343-3434; Jung Hwan Baek: http://orcid.org/0000-0003-0480-4754; Eun Ju Ha: http://orcid.org/0000-00021234-2919; Jee Won Park: http://orcid.org/0000-0002-7194-2826; Jeong Hyun Lee: http://orcid.org/0000-0002-0021-4477; Dong Eun Song: http://orcid.org/0000-00029583-9794

\section{Conflict of Interest}

No potential conflict of interest relevant to this article was reported.

\section{References}

1. American Thyroid Association (ATA) Guidelines Taskforce on Thyroid Nodules and Differentiated Thyroid Cancer, Cooper DS, Doherty GM, Haugen BR, Kloos RT, Lee SL, et al. Revised American Thyroid Association management guidelines for patients with thyroid nodules and differentiated thyroid cancer. Thyroid 2009;19:11671214.

2. Gharib H, Papini E, Paschke R, Duick DS, Valcavi R, Hegedus L, et al. American Association of Clinical Endocrinologists, Associazione Medici Endocrinologi, and EuropeanThyroid Association medical guidelines for clinical practice for the diagnosis and management of thyroid nodules. Endocr Pract 2010;16 Suppl 1:1-43.

3. Moon WJ, Baek JH, Jung SL, Kim DW, Kim EK, Kim JY, et al. Ultrasonography and the ultrasound-based management of thyroid nodules: consensus statement and recommendations. Korean J Radiol 2011;12:1-14.

4. Ko MS, Jeong KS, Shong YK, Gong GY, Baek JH, Lee JH. Collapsing benign cystic nodules of the thyroid gland: sonographic differentiation from papillary thyroid carcinoma. AJNR Am J Neuroradiol 2012;33:124-127.

5. Koo JH, Shin JH, Han BK, Ko EY, Kang SS. Cystic thyroid nodules after aspiration mimicking malignancy: sonographic characteristics. J Ultrasound Med 2010;29:1415-1421.

6. Sohn YM, Kim EK, Moon HJ, Kim SJ, Kwak JY. Suspiciously malignant findings on ultrasound after fine needle aspiration biopsy in a thyroid nodule with initially benign ultrasound and cytologic result: to repeat or to follow-up. Clin Imaging 2011;35:470-475.

7. Park NH, Kim DW, Park HJ, Lee EJ, Park JS, Park SI, et al. Thyroid cysts treated with ethanol ablation can mimic malignancy during sonographic follow-up. J Clin Ultrasound 2011;39:441-446.

8. Ha EJ, Baek JH, Lee JH, Song DE, Kim JK, Shong YK, et al. Sonographically suspicious thyroid nodules with initially benign cytologic results: the role of a core needle biopsy. Thyroid
2013;23:703-708

9. Kwak JY, Jung I, Baek JH, Baek SM, Choi N, Choi YJ, et al. Image reporting and characterization system for ultrasound features of thyroid nodules: multicentric Korean retrospective study. Korean J Radiol 2013;14:110-117.

10. Moon WJ, Jung SL, Lee JH, Na DG, Baek JH, Lee YH, et al. Benign and malignant thyroid nodules: US differentiation: multicenter retrospective study. Radiology 2008;247:762-770.

11. Yeon JS, Baek JH, Lim HK, Ha EJ, Kim JK, Song DE, et al. Thyroid nodules with initially nondiagnostic cytologic results: the role of core-needle biopsy. Radiology 2013;268:274-280.

12. Choi YJ, Baek JH, Ha EJ, Lim HK, Lee JH, Kim JK, et al. Differences in risk of malignancy and management recommendations in subcategories of thyroid nodules with atypia of undetermined significance or follicular lesion of undetermined significance: the role of ultrasound-guided core-needle biopsy. Thyroid 2014;24:494501.

13. Sung JY, Na DG, Kim KS, Yoo H, Lee $H$, Kim JH, et al. Diagnostic accuracy of fine-needle aspiration versus core-needle biopsy for the diagnosis of thyroid malignancy in a clinical cohort. Eur Radiol 2012;22:1564-1572.

14. Na DG, Kim JH, Sung JY, Baek JH, Jung KC, Lee H, et al. Coreneedle biopsy is more useful than repeat fine-needle aspiration in thyroid nodules read as nondiagnostic or atypia of undetermined significance by the Bethesda system for reporting thyroid cytopathology. Thyroid 2012;22:468-475.

15. Polyzos SA, Anastasilakis AD. Clinical complications following thyroid fine-needle biopsy: a systematic review. Clin Endocrinol (Oxf) 2009;71:157-165.

16. Jang EK, Song DE, Gong G, Baek JH, Choi YM, Jeon MJ, et al. Positive cytology findings and a negative histological diagnosis of papillary thyroid carcinoma in the thyroid: is it a false-positive cytology or a disappearing tumor? Eur Thyroid I 2013;2:203-210.

17. Eze OP, Cai G, Baloch ZW, Khan A, Virk R, Hammers LW, et al. Vanishing thyroid tumors: a diagnostic dilemma after ultrasonography-guided fine-needle aspiration. Thyroid 2013;23:194-200.

18. Jung $S L$, Jung CK, Kim SH, Kang BJ, Ahn KJ, Kim BS, et al. Histopathologic findings related to the indeterminate or inadequate results of fine-needle aspiration biopsy and correlation with ultrasonographic findings in papillary thyroid carcinomas. Korean J Radiol 2010;11:141-148.

19. Chen SJ, Yu SN, Tzeng JE, Chen YT, Chang KY, Cheng KS, et al. Characterization of the major histopathological components of thyroid nodules using sonographic textural features for clinical diagnosis and management. Ultrasound Med Biol 2009;35:201208.

20. Jaragh M, Carydis VB, MacMillan C, Freeman J, Colgan TJ. Predictors of malignancy in thyroid fine-needle aspirates "cyst fluid only" cases: can potential clues of malignancy be identified? Cancer 
2009;117:305-310.

21. Alexander EK, Hurwitz $S$, Heering JP, Benson CB, Frates MC, Doubilet PM, et al. Natural history of benign solid and cystic thyroid nodules. Ann Intern Med 2003;138:315-318.

22. Kuma K, Matsuzuka F, Kobayashi A, Hirai K, Morita S, Miyauchi A, et al. Outcome of long standing solitary thyroid nodules. World I Surg 1992;16:583-587.

23. Kuma K, Matsuzuka F, Yokozawa T, Miyauchi A, Sugawara M. Fate of untreated benign thyroid nodules: results of long-term follow-up. World J Surg 1994;18:495-498.

24. Ito Y, Amino N, Hirokawa M, Kobayashi K, Miya A, Miyauchi A. A solid thyroid benign nodule that showed a significant decrease in size and ultrasonographic findings mimicking papillary carcinoma during 16-year follow-up. Endocr I 2011;58:19-22.

25. Screaton NJ, Berman LH, Grant JW. US-guided core-needle biopsy of the thyroid gland. Radiology 2003;226:827-832.

26. Nasrollah N, Trimboli P, Guidobaldi L, Cicciarella Modica DD, Ventura C, Ramacciato G, et al. Thin core biopsy should help to discriminate thyroid nodules cytologically classified as indeterminate: a new sampling technique. Endocrine 2013;43:659-665.

27. Park KT, Ahn SH, Mo JH, Park YJ, Park DJ, Choi SI, et al. Role of core needle biopsy and ultrasonographic finding in management of indeterminate thyroid nodules. Head Neck 2011;33:160-165. 